Published in "Journal of Aerosol Science 38(11): 1163-1168, 2007"

which should be cited to refer to this work.

\title{
An improved low-flow thermodenuder
}

\author{
Martin Fierz $^{\mathrm{a}, *}$, Martine G.C. Vernooij ${ }^{\mathrm{b}, \mathrm{c}}$, Heinz Burtscher ${ }^{\mathrm{a}}$ \\ a Institute for Aerosol and Sensor Technology, University of Applied Sciences Northwestern Switzerland, CH-5210 Windisch, Switzerland \\ ${ }^{\mathrm{b}}$ Technical Mineralogy, Fribourg University, CH-1700 Fribourg, Switzerland \\ ${ }^{\mathrm{c}}$ EMPA, Air Pollution/Environmental Technology, CH-8600 Dübendorf, Switzerland
}

\begin{abstract}
Thermodenuders are used to remove the volatile fraction of an aerosol. All designs until now have a cooled adsorption section where the volatile material is trapped, but theoretical considerations suggest that the adsorption section should be heated. Therefore, we built a thermodenuder with a heated adsorption section. We tested its performance with respect to particle penetration and its ability to remove DEHS coated onto $\mathrm{NaCl}$ nuclei. The measured losses are lower than in previously published designs and the DEHS removal appears to be satisfactory. Additionally, the new thermodenuder is practical for field use thanks to its small size. It should therefore be a good alternative to previous designs.
\end{abstract}

Keywords: Thermodenuder; Volatility

\section{Introduction}

Conventional thermodenuders (e.g. Burtscher et al., 2001; Wehner, Philippin, \& Wiedensohler, 2002 and the commercial models by Dekati and TSI) consist of a heating section followed by an adsorption section containing activated carbon, which is either actively or passively cooled. This setup necessarily introduces a rapid temperature drop at the connection of the heated and cooled section. Such a rapid temperature drop is undesirable for two reasons: first, it can lead to a turbulent flow which in turn will cause high thermophoretic losses. Second, the temperature drop is in general a more rapid process than the removal of the volatile species; the temperature drop is governed by the diffusion coefficient of the carrier gas molecules, while the removal of the volatile species is governed by the diffusion coefficient of the volatile species, which is smaller than the diffusion coefficient of air. Therefore, recondensation (either on available solid particles, or through homogenous nucleation) will inevitably take place, unless the gas has been heated well above the boiling point of the volatile species. After recondensation takes place, the remainder of the adsorption section has no further effect on the aerosol. For example, in the Burtscher thermodenuder the gas temperature is reported to drop to $50^{\circ} \mathrm{C}$ or less after only $10 \mathrm{~cm}$ of the $50 \mathrm{~cm}$ long adsorption section at flow rates below $2 \mathrm{lpm}$. If this is true, then the remainder of the adsorption section is of no further use, and only causes higher particle losses.

It has been suggested that an insufficient residence time in the heating section may cause an incomplete removal of volatile material in a thermodenuder because the volatile material needs some time to evaporate (An, Pathak, Lee, \&

\footnotetext{
* Corresponding author. Tel.: +41564624596.

E-mail address: martin.fierz@fhnw.ch (M. Fierz).
} 


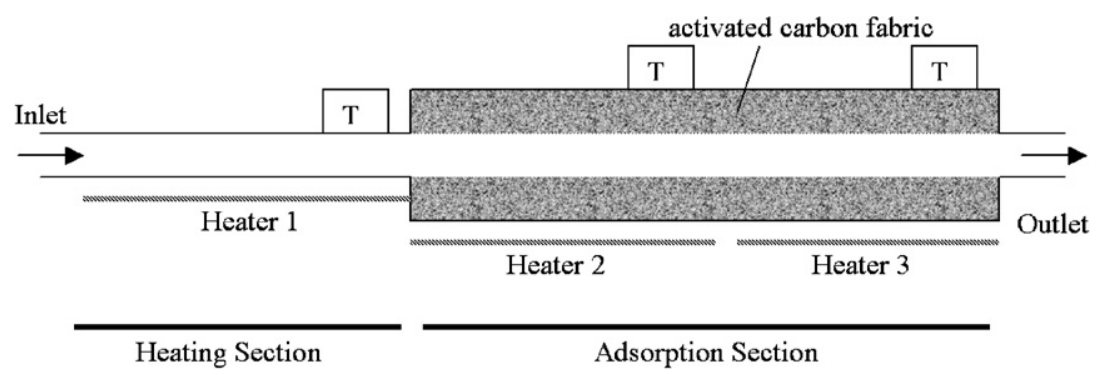

Fig. 1. Schematic layout of the thermodenuder. The temperature is measured with Pt1000 sensors $10 \mathrm{~mm}$ before the end of each section (marked with a T).

Pandis, 2007; Wehner et al., 2002). In our opinion, the rapid cooling taking place in the adsorption section is another important reason for incomplete removal of volatile material in a thermodenuder. Therefore, we constructed a new thermodenuder, which has a heated adsorption section and consequently does not exhibit the rapid gas temperature drop seen in previous designs.

\section{Construction}

The design of our new thermodenuder is shown in Fig. 1. Just like conventional thermodenuders, it consists of a heating section followed by an adsorption section. In contrast to existing designs, we added two further independent heaters on the outside of the adsorption section. The three independent heaters of our thermodenuder give a greater flexibility in the choice of the temperature profile in the instrument. The heating section is a stainless steel tube, $10 \mathrm{~cm}$ long with an inner diameter of $8 \mathrm{~mm}$. The adsorption section is $20 \mathrm{~cm}$ long, and consists of a wire mesh cylinder with a diameter of $8 \mathrm{~mm}$, covered with activated carbon fabric (Kynol ACC-507-20), and mounted centrally inside a $12 \mathrm{~mm}$ inner diameter stainless steel tube. The stainless steel tubes have very thin walls $(0.5 \mathrm{~mm})$ to minimize the power necessary to heat the instrument. Three thermofoil heaters (Minco) are wrapped around the outside of the stainless steel tube and clamped onto the tube. For each of these heaters, the temperature is measured with a Pt1000 sensor $10 \mathrm{~mm}$ before the end of the heating section. The thermofoil heaters can be used up to $250{ }^{\circ} \mathrm{C}$, but not higher, which is a slight limitation of our current design. The adsorption section is much shorter than in previous designs, since apparently the short "effective adsorption section" (where gas temperatures are high) was sufficient to remove the volatile material in previous designs. Additionally, a shorter thermodenuder has lower diffusion losses than a longer one. The entire instrument including control electronics and a battery has a size of $350 \times 250 \times 45 \mathrm{~mm}$, and weighs about $3 \mathrm{~kg}$.

\section{Theory}

In the literature on thermodenuders, residence time in the thermodenuder has been mentioned as a critical parameter in the instrument's performance (An et al., 2007; Wehner et al., 2002). The temperature profile in the thermodenuder is also important. It depends on the flow rate, and a simple estimate can be made for the necessary length of the thermodenuder at a given flow rate: given a thermodenuder heating section of radius $r$ at a temperature $T$ and an air flow rate $Q$ through the instrument, what length $L$ should it have so that the gas temperature reaches $T$ ? Heat transfer is a diffusion process, and the mean displacement by diffusion $x$ in the time $t$ is given by

$$
\left\langle\mathrm{x}^{2}\right\rangle=D \cdot t,
$$

where $D$ is the diffusion coefficient of the carrier gas, e.g. for air $0.2 \mathrm{~cm}^{2} / \mathrm{s}$. The residence time $t$ is

$$
t=\frac{V}{Q}=\frac{L \cdot \pi \cdot r^{2}}{Q} \text {. }
$$

If the heat should diffuse through the entire tube cross-section, $x$ must equal $r$. Solving for $L$ we get

$$
L=\frac{Q}{\pi \cdot D} \quad \text { or } \quad L[\mathrm{~cm}]=26.5 \cdot Q[\mathrm{lpm}] .
$$


a

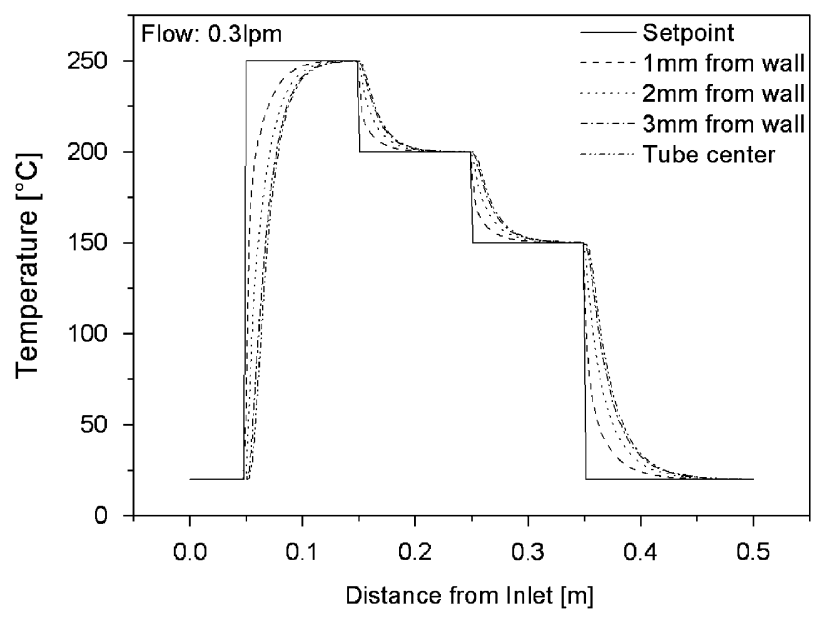

b

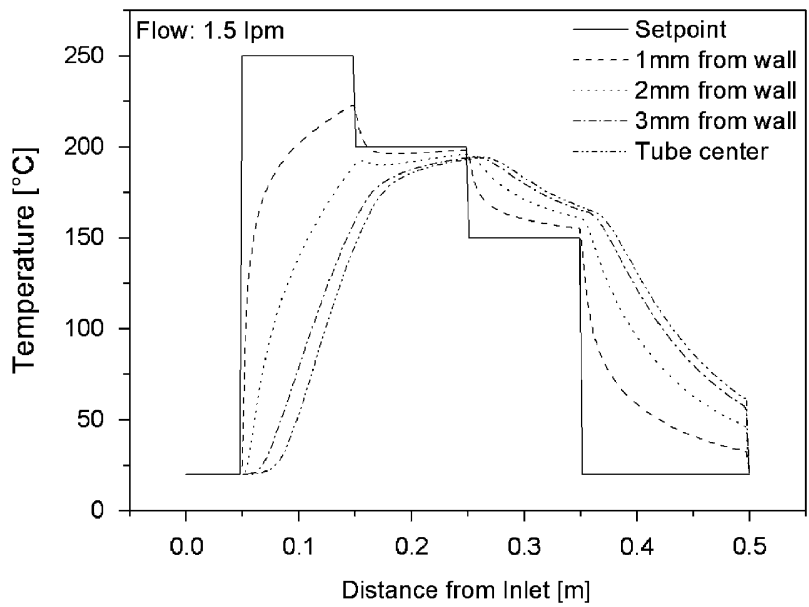

Fig. 2. (a) Calculated temperature profile in the thermodenuder as function of radial position and distance from inlet at a flow rate of 0.3 lpm. (2b) Same as $(2 \mathrm{a})$, but for a flow rate of $1.5 \mathrm{lpm}$.

In other words, a thermodenuder to be used at a flow rate of $1 \mathrm{lpm}$ should have a heating section of approximately $26 \mathrm{~cm}$ length; this length is independent of the tube diameter. According to this calculation, our thermodenuder with its $10 \mathrm{~cm}$ heating section should not be operated at flow rates above $\sim 0.38 \mathrm{lpm}$. This qualitative estimate neglects the expansion of the gas with temperature and the temperature dependence of the diffusion coefficient, but these two effects nearly cancel each other since the diffusion coefficient increases with temperature.

Obviously, this estimate is quite crude, and to quantify it more precisely, we calculated the temperature profile along the aerosol flow tube throughout the entire length of the thermodenuder with a commercial finite element program (COMSOL multiphysics 3.3). In our opinion, this is more accurate than the notoriously difficult experimental measurement of gas temperature in the thermodenuder (Benedict, 1977). The model includes the expansion of the air as it heats up, and the changes in thermal conductivity and viscosity of air (using the non-isothermal flow application mode of COMSOL). We made two simplifying assumptions: (1) The thermodenuder was modeled as a tube with constant diameter of $8 \mathrm{~mm}$ and three heating sections and (2) the tube wall temperature in each heating section was assumed to be equal to the setpoint temperature of that section. These assumptions are not fulfilled exactly, but this has no consequences for the conclusions. The temperature profiles in the modeled thermodenuder are shown in Figs. 2a and $b$ for flow rates of 0.3 and $1.5 \mathrm{lpm}$, respectively, as a function of the radial location in the tube. The gas temperature reaches the setpoint at $0.3 \mathrm{lpm}$, but remains far below the setpoint at $1.5 \mathrm{lpm}$. Additionally, different gas streamlines experience very different temperature profiles during their passage through the thermodenuder at the higher flow rate. The finite element calculation confirms the analytical estimate, and thus Eq. (3) can be used to select appropriate flow rates for other thermodenuders - or to detect inappropriate flow rates. This may explain the observations by (An et al., 2007) where a flow rate of $10 \mathrm{lpm}$ was used in a $55 \mathrm{~cm}$ long thermodenuder.

\section{Experimental}

To assess the performance of our thermodenuder, we performed two different experiments: first, we measured particle losses in the thermodenuder both at room temperature and at an elevated temperature (heaters set to $200 / 150 / 100^{\circ} \mathrm{C}$ ) as a function of particle size in the size range from 10 to $100 \mathrm{~nm}$. Larger particles were not considered, since losses are greatest for small particles. The losses were measured as follows (see Fig. 3); $\mathrm{NaCl}$ particles were generated by nebulizing a $\mathrm{NaCl}$ solution and passing the output through a diffusion dryer. A particle size was selected with the DMA (TSI model 3080). Two CPC's (TSI model 3025) sampled the aerosol before and after the thermodenuder for 1 min each, producing 60 one-second particle concentrations. From these, an average particle concentration and a statistical error for the average particle concentration were computed. The particle penetration is then quantified as ( $\mathrm{pt} / \mathrm{ccm}$ after thermodenuder)/(pt/ccm before thermodenuder). We corrected for different lengths of tubing leading to 


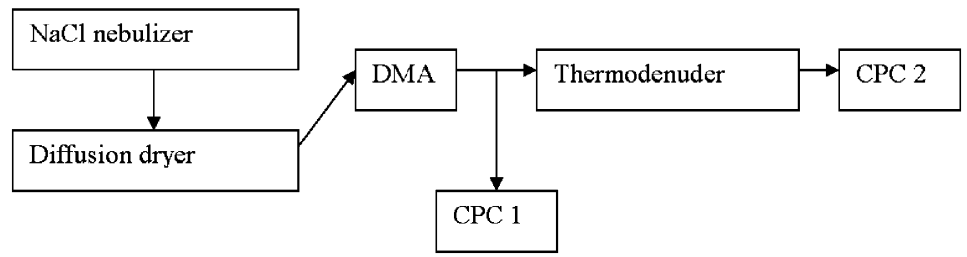

Fig. 3. Experimental setup for loss measurements.

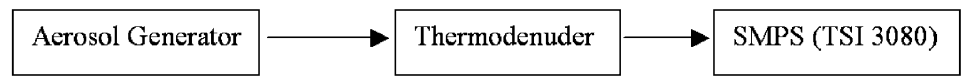

Fig. 4. Experimental setup for volatile material removal.

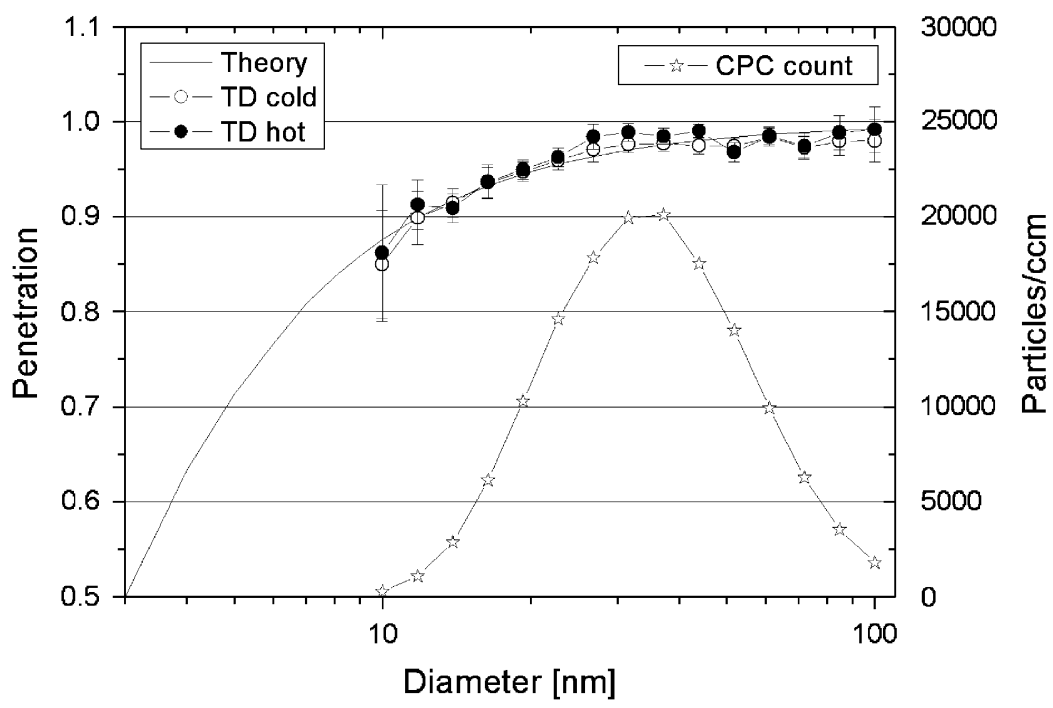

Fig. 5. Particle losses as function of particle size at a flow of $0.315 \mathrm{lpm}$. TD cold is at room temperature, TD hot at a setting of $200 / 150 / 100{ }^{\circ} \mathrm{C}$, respectively, for the three heating sections. The right-hand scale shows the number of particles/ccm measured with the CPC before the thermodenuder.

the two CPC's and a possible systematic counting difference between the two CPC's by replacing the thermodenuder with a tube connector and repeating the experiment. The difference in penetration between the tube connector and the thermodenuder represents the corrected penetration efficiency of the thermodenuder.

Second, we tested the removal efficiency of volatile material in the thermodenuder with aerosol produced with a TSI model 3475 condensation monodisperse aerosol generator (see Fig. 4): This generator produces aerosol consisting of $\mathrm{NaCl}$ nuclei with a coating of DEHS (Di-Ethyl-Hexyl-Sebacat, $\mathrm{C}_{26} \mathrm{H}_{50} \mathrm{O}_{4}$ ). DEHS is a large molecule with a boiling point of $300^{\circ} \mathrm{C}$ and thus not easy to volatilize; the $\mathrm{NaCl} / \mathrm{DEHS}$ aerosol is therefore a good test substance for thermodenuders because it represents a worst-case scenario. The $\mathrm{NaCl} / \mathrm{DEHS}$ aerosol was measured at the outlet of the thermodenuder with an SMPS system (TSI) for three different cases: (1) bare $\mathrm{NaCl}$ nuclei, thermodenuder off (2) $\mathrm{NaCl}$ nuclei coated with DEHS, thermodenuder off, and (3) $\mathrm{NaCl}$ nuclei coated with DEHS, thermodenuder on, operated at different temperature settings. The aerosol generator was operated in a fume hood, and the particles were transported to the experiment through a $4 \mathrm{~m}$ long tube.

\section{Results}

Particle losses are shown in Fig. 5 for a flow rate of $0.315 \mathrm{lpm}$ through the thermodenuder. The figure shows the sizedependent particle loss in the thermodenuder at room temperature (closed symbols) and at a setting of $200 / 150 / 100{ }^{\circ} \mathrm{C}$ 
a

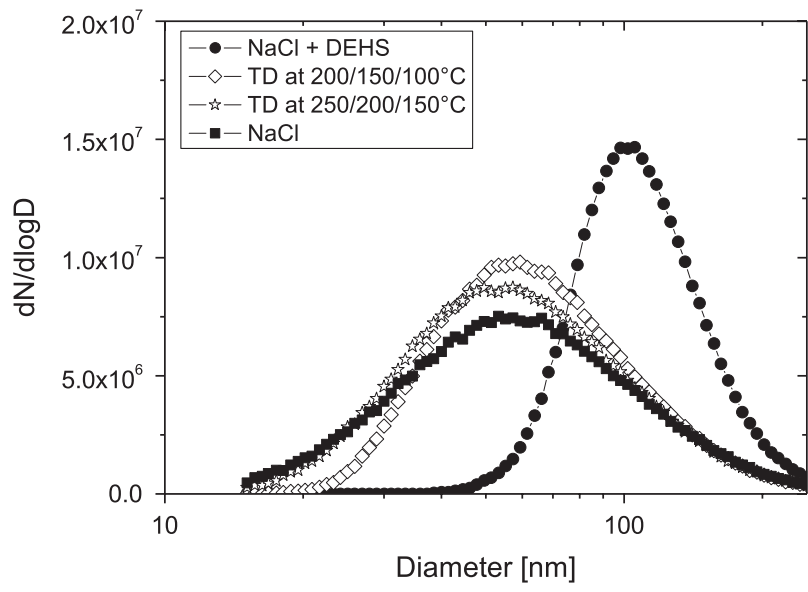

b

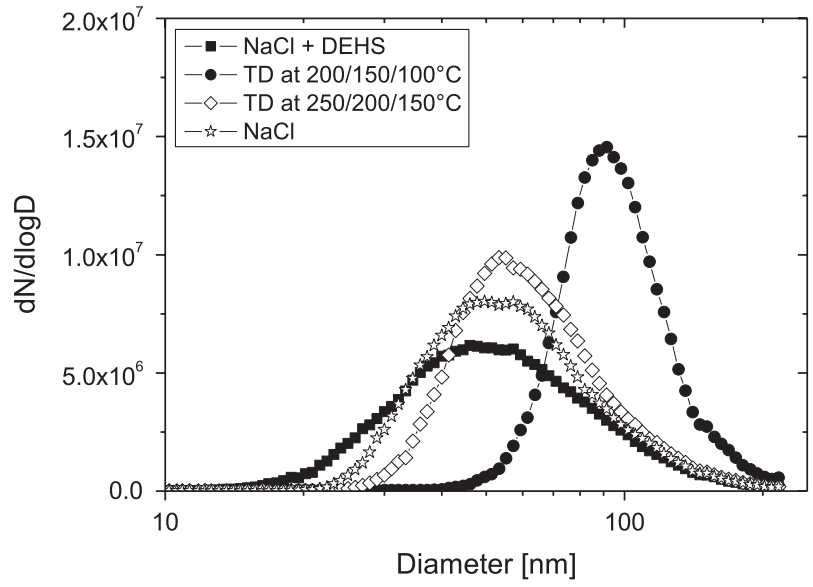

Fig. 6. (a) Particle size distribution of $\mathrm{NaCl} / \mathrm{DEHS}$ aerosol at the outlet of the thermodenuder at $0.3 \mathrm{lpm}$. (6b) Same as (6a) but $1.5 \mathrm{lpm}$ flow.

(open symbols). The error bars are computed from the statistical errors in the CPC counts as described in the experimental section. The theoretical particle loss by diffusion for a tube of $39 \mathrm{~cm}$ length at $0.315 \mathrm{lpm}$ flow is plotted as a line.

Fig. 6a shows SMPS spectra of the aerosol size distribution measured after the thermodenuder in the experiment with $\mathrm{NaCl} / \mathrm{DEHS}$ aerosol at a flow of $0.3 \mathrm{lpm}$ through the thermodenuder. Fig. $6 \mathrm{~b}$ shows the same for a flow of $1.5 \mathrm{lpm}$.

\section{Discussion}

The loss measurements show that our thermodenuder is operating at the theoretical limit; the losses measured both in the cold and hot state correspond exactly to the theoretical diffusion losses in a tube. There are no visible thermophoretic losses. At first sight this might be surprising, however, a perfectly laminar flow which is first heated and then cooled should not show any thermophoretic losses at all; thermophoresis forces the aerosol particles toward the center of the flow in the heating section and then back toward the tube wall again at places where the gas cools down. The net effect should be zero if the flow is truly laminar. If the flow is turbulent at any point, the aerosol particles will be evenly distributed in the tube and thermophoretic losses become unavoidable when the gas cools down. The theoretical curve in Fig. 5 is extended beyond the experimental measurement range $(10 \ldots 100 \mathrm{~nm})$ down to $3 \mathrm{~nm}$, where it reaches a loss of $50 \%$. Our thermodenuder should therefore be suitable for detecting solid cores of sizes down to $3 \mathrm{~nm}$.

Our experiments on DEHS removal from $\mathrm{NaCl}$ cores show that the DEHS removal remains incomplete at a flow rate of $1.5 \mathrm{lpm}$, but is (nearly) complete at the lower flow rate of $0.3 \mathrm{lpm}$. This was to be expected from the temperature profile calculations which show that the instrument should not reach the temperature setpoints at this gas flow rate. By calculating the volume concentrations from the SMPS spectra, we find that at a flow rate of $1.5 \mathrm{lpm}, 94 \%$ of the DEHS was removed. At $0.3 \mathrm{lpm}$ flow rate, the removed DEHS fraction could not be calculated, since the volume concentration of the bare $\mathrm{NaCl}$ nuclei was slightly larger (by a few percent) than that of the sample that passed through the thermodenuder. This could be due to a small instability of the aerosol generator, or just to experimental uncertainty of an SMPS scan. However, even at the lower flow rate, the size spectrum of the pure $\mathrm{NaCl}$ particles is not exactly the same as the size spectrum of the coated and denuded $\mathrm{NaCl}$ particles. The small difference is probably due to incomplete DEHS removal, but might also originate from other sources, for example, the aerosol generator may not have been perfectly stable over the time where the experiments were performed. Also, the transport efficiency of the particles through the long tubing from the generator to the measurement setup is slightly higher for DEHS-coated particles than for the bare $\mathrm{NaCl}$ nuclei.

As an outlook, we would like to mention that it is well possible that the heating section of the thermodenuder is superfluous and that the design could be simplified further by constructing a thermodenuder consisting of a heated adsorption section only. 


\section{Conclusions}

We have built a thermodenuder with a heated adsorption section, whereas previous designs had cooled adsorption sections. Our design gives us more flexibility for setting the temperature profile along the thermodenuder, and allows us to retain the volatile species in the gas phase over the length of the entire adsorption section. In previous designs, the temperature in the adsorption section was reported to drop rapidly, which may lead to recondensation of volatile species on nonvolatile particles. From this it follows that a thermogram, i.e. the measurement of the size distribution after the thermodenuder for different temperatures to detect at what temperature the volatile species desorb, will be better defined with our design.

We also developed a simple estimate (Eq. (3)) for the necessary instrument length for a given flow rate, and verified the estimate with a finite element calculation. The simple estimate is also a useful tool to select appropriate flow rates for existing thermodenuders. Additionally, Eq. (3) shows that while the temperature profile depends on the flow rate, it is independent of the tube diameter. Therefore, experiments that are supposed to measure the influence of residence time should be performed with different tube diameters, rather than with different flow rates in the same instrument.

Our thermodenuder has minimal particle losses, i.e. it shows the diffusion losses expected from a tube of the length of the thermodenuder, but no more. The losses are nearly an order of magnitude smaller than in previously published designs. Extrapolation of the experimental data indicates that our thermodenuder should be suitable to detect nonvolatile cores as small as $3 \mathrm{~nm}$ thanks to its low-loss-design, which could be useful if one were to look for tiny solid cores in nucleation mode particles.

The experiments with $\mathrm{NaCl} / \mathrm{DEHS}$ show that the thermodenuder removes DEHS efficiently at a flow rate of $0.3 \mathrm{lpm}$, despite its small size compared to previous thermodenuders, which makes it very suitable for field measurements.

\section{References}

An, W. J., Pathak, R. K., Lee, B.-H., \& Pandis, S. N. (2007). Aerosol volatility measurement using an improved thermodenuder: Application to secondary organic aerosol. Journal of Aerosol Science, 38, 305-314.

Benedict, R. P. (1977). Fundamentals of temperature, pressure and flow measurements. New York: Wiley.

Burtscher, H., Baltensperger, U., Buckowiecki, N., Cohn, P., Hüglin, C., Mohr, M. et al. (2001). Separation of volatile and non-volatile aerosol fractions by thermodesorption: Instrumental development and applications. Journal of Aerosol Science, 32, 427-442.

Wehner, B., Philippin, S., \& Wiedensohler, A. (2002). Design and calibration of a thermodenuder with an improved heating unit to measure the size-dependent volatile fraction of aerosol particles. Journal of Aerosol Science, 33, 1087-1093. 